\title{
Numerical analysis of the forming process of the bearing capacity of the auxiliary pile foundation in Permafrost area
}

\author{
Sun Jianzhong ${ }^{1}$, Guo Chunxiang ${ }^{1}$, Wang $\mathrm{Xu}^{1}$, Zhang Weijia ${ }^{1}$ \\ ${ }^{1}$ School of civil engineering, Lanzhou Jiaotong University, lanzhou 730070, Gansu,China
}

\begin{abstract}
Bore Cast-in-place Piles broke the original water and heat balance state of the stratum in the bridge construction of Qinghai Tibet railway. The settlement of a bridge pile foundation was relatively large after more than ten years of operation. It was found that there is confined water in the foundation soil after investigation. Engineers planned to add auxiliary piles at the original pile side to reduce the settlement of the pile foundation. This paper studied the temperature change, bearing capacity formation rule and longterm bearing capacity change trend of the new pile-soil system after adding auxiliary piles on the original foundation, which provides certain theoretical basis and reference basis for engineering practice. A threedimensional model of a bridge pile foundation was established by numerical method. Considering the influence of atmospheric temperature, hydrogeological conditions, concrete temperature into the mold, and the temperature of underground confined water, based on the heat transfer theory, the boundary conditions and initial conditions are given. The influence of the change of ground temperature field and the change of pile-soil interface temperature on the bearing capacity of the foundation was studied after the auxiliary pile was poured. The analysis shows that the measure to increase the bearing capacity by adding auxiliary piles is a double-edged sword. On the one hand, the auxiliary piles themselves constitute the bearing capacity together with the original pile foundation after thawing, on the other hand, the auxiliary piles are constructed by the method of pouring concrete in the field. The hydration heat of concrete makes the temperature of the original foundation soil rise, and reduces its bearing capacity. The whole bearing capacity will not be increased at the initial stage, but also will be temporarily reduced, and the whole bearing capacity will be formed after the frozen soil is frozen back in the later stage.
\end{abstract}

\section{INTRODUCTION}

Along with engineering activities conducted in permafrost regions of the Qinghai-Tibet Plateau, the temperature of permafrost goes up, the active layer gets thicker, and the underground ice melts, and all these changes will jeopardize the stability of subgrade engineering. Since a vast amount of artificially filling pedestal piles have been applied during the construction of Qinghai-Tibet Railway, the frozen soil surrounding those piles can be thawed by the high temperature of casting concrete and heat of hydration, which will be frozen again over time. The refrozen pile-soil interface can equip the pile foundation with certain bearing capacity.

Some scholars have already preceded test and numerical modeling on the refreezing performance and bearing capacity of single piles in the permafrost regions. $\mathrm{Wu}$ et al. ${ }^{[1]}$ calculate the temperature field during the refreezing process of single cast-in-situ pile in permafrost regions of the Qinghai-Tibet Plateau with classic humid climate by using finite element analysis method, with the changes of pile temperature and at different depths and refreezing moments provided. Based on the Design Specifications, they analyze the influence of the temperature field changes on the bearing capacity of single pile and the construction process during the single pile refreezing process, and the conclusion can serve as the theoretical basis for the formulation of bridge construction plans in permafrost regions; Guo et al. ${ }^{[2]}$ come to the conclusion that solar radiation and climate warming can warm up the pile-soil interface and decrease the bearing capacity of single piles by applying the finite element analysis method; the longer the exposed pile is, the more the solar radiation is absorbed, the higher the temperature goes up, and the lower the bearing capacity is. Such influence is especially effective in winter, while the temperature does not go up too much in summer. The initial annual average temperature has significant influence on the bearing capacity of pile foundation. With the increase of initial annual average temperature per degree Celsius, the bearing capacity of pile foundation in summer will decrease by $800-1,000 \mathrm{kN}$, and $400-700 \mathrm{kN}$ in summer. Based on the practical conditions of a bridge, this paper finds that after several years of service of the original pile foundation, the lower limit depth of permafrost under each pier in permafrost varies greatly, with the minimum depth of $19.9 \mathrm{~m}$, the maximum depth of $39.5 \mathrm{~m}$, and the majority of about $30 \mathrm{~m}$. Furthermore, the

\footnotetext{
* Corresponding author: sunjzh@mail.lzjtu.cn
} 
confined water is found under the frozen layer of each pier. The permafrost decay rate, along with the huge changes of permafrost environment, decreases, and the safety margin of pile foundation declines to certain degree. In order to ensure the long-term stability of projects, the foundation of No.4-No.8 pier has been consolidated, with 4 pile foundations ( $\phi 1 \mathrm{~m}$ ) added at both sides of piers to strengthen the bearing capacity of pile foundation. Auxiliary piles for No.4-No.6 pier are designed to be $40 \mathrm{~m}$ long, and No.7 and No.8 pier piles are $45 \mathrm{~m}$ long. The reinforced concrete bearing platform has been adopted, with drill nails and scabbling set at the side of existing bearing platform to link with newly built bearing platform, thus being an integrated foundation and sharing the imposed force. However, there is little in-depth study on the influence of the construction of auxiliary piles and refreezing process on the permafrost temperature field, temperature variation of pile-soil interface of original foundation and its influence on the bearing capacity.

Therefore, this paper, after taking consideration of solar radiation, air convection, temperature of casting concrete and underground confined water, and based on the heat transfer theory, deals with the influence of changes of geothermal field upon the construction of auxiliary piles and temperature changes of pile-soil interface on the bearing capacity of the foundation at the regions of Qinghai -Tibet Plateau with classic humid climate under warm season.

\section{CALCULATION MODEL AND BOUNDARY CONDITIONS}

\subsection{Numerical model and soil sample parameters}

According to the symmetry of the bridge pile foundation, part of it is taken as the numerical simulation model, as shown in Figure 6.2. The underground part of the original pile foundation is $22 \mathrm{~m}$ long, the exposed part is $2 \mathrm{~m}$ long, and the auxiliary pile foundation is $40 \mathrm{~m}$ long. The calculation model is $60 \mathrm{~m}$ below the ground.

Please refer to Figure 1 for the model calculation range schematic diagram and Figure 2 for finite element model, and Table 1 in the following page for the hydrological and geological data about the pile foundation and thermodynamic parameters.

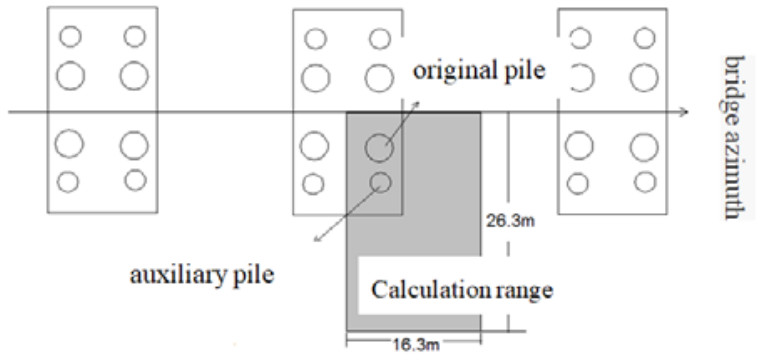

Fig. 1. The computational region of the model

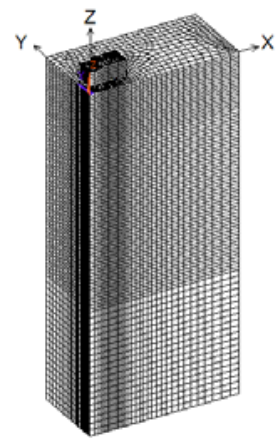

Fig. 2. The numerical analysis mode

\subsection{Concrete hydration heat of casting auxiliary piles}

When casting auxiliary piles, the concrete hydration heat lasts for a period of time from the moment of heat release to the whole generation of hydration heat, and such duration reflects the heat release rate of the cement, which can be a feature of cement hydration heat. There are two ways to describe the heat release process of cement, namely, exponential and fractional. According to the trial, the exponential expression is closer to the actual conditions, therefore, the exponential mathematical expression is adopted:

$$
Q_{t}=Q\left(1-e^{-m t}\right)
$$

Qtrefers to the cement calorific value per unit volume at the age of $\mathrm{t}$, expressed in $\mathrm{J} \bullet \mathrm{m}-3$; Q refers to the heat release of final cement hydration heat per unit volume, expressed in $\mathrm{J} \bullet \mathrm{m}-3$; $\mathrm{m}$ refers to the heat release rate of cement hydration heat. The expression of final cement heat release is

$$
Q=\Delta T_{\max } C_{c}
$$

Tmaxrefers to the adiabatic temperature rise of concrete $\left({ }^{\circ} \mathrm{C}\right) ; \mathrm{C}_{\mathrm{c}}$ refers to the average specific heat of concrete, expressed in $\mathrm{J} \bullet\left(\mathrm{kg} \bullet{ }^{\circ} \mathrm{C}\right)^{-1}$.

Heat generation rate of concrete per unit volume $\mathrm{q}_{\mathrm{v}}$ $\left(\mathrm{W} \cdot \mathrm{m}^{-3}\right)$ :

$$
q_{v}=\frac{d Q_{t}}{d t}=C_{c} \Delta T_{\max } m e^{-m t}
$$

The variation of heat release rate of concrete hydration heat along with the pile casting time is shown in Figure 3. 
Tab. 1. Hydrogeological condition and thermal physical parameters of pile foundation

\begin{tabular}{|c|c|c|c|c|c|c|c|c|}
\hline Material & $\begin{array}{l}\text { Depth } \\
\text { (m) }\end{array}$ & $\begin{array}{c}\text { Water } \\
\text { Content } \\
\%\end{array}$ & $\begin{array}{l}\text { Dry Density } \\
\left(\mathrm{kg} \cdot \mathrm{m}^{-3}\right)\end{array}$ & $\begin{array}{c}\lambda_{s} \\
\left(\mathrm{~kJ} \cdot \mathrm{m}^{-3} \cdot{ }^{\circ} \mathrm{C}\right)\end{array}$ & $\begin{array}{c}{ }_{L} \\
\left(\mathrm{~kJ} \cdot \mathrm{m}^{-3} \cdot{ }^{\circ} \mathrm{C}\right)\end{array}$ & $\begin{array}{c}C_{s} \\
\left(k J \cdot m^{-3} \cdot{ }^{\circ} \mathrm{C}\right)\end{array}$ & $\begin{array}{c}C_{L} \\
\left(k J \cdot m^{-3} \bullet{ }^{\circ} \mathrm{C}\right)\end{array}$ & $\begin{array}{c}C_{f u} \\
\left(\mathrm{~kJ} \cdot \mathrm{m}^{-3} \cdot{ }^{\circ} \mathrm{C}\right)\end{array}$ \\
\hline Loam & $0 \sim 1.5$ & 40.0 & 1200 & 4059 & 5690 & 2830 & 2230 & 62254 \\
\hline $\begin{array}{l}\text { Peat-contained } \\
\text { loam }\end{array}$ & $1.5 \sim 3.5$ & 60.0 & 900 & 2050 & 3054 & 2480 & 1980 & 78125 \\
\hline $\begin{array}{l}\text { Aggregate- } \\
\text { contained loam }\end{array}$ & $3.5 \sim 8.0$ & 24.5 & 1500 & 5105 & 5648 & 2480 & 1871 & 38258 \\
\hline $\begin{array}{l}\text { Differentiated bed } \\
\text { rock }\end{array}$ & $>8$ & 4.0 & 1500 & 9720 & 9720 & 2290 & 2290 & 39865 \\
\hline $\begin{array}{c}\text { Reinforced } \\
\text { concrete }\end{array}$ & & & 2500 & 6264 & 6264 & 2300 & 2300 & \\
\hline
\end{tabular}

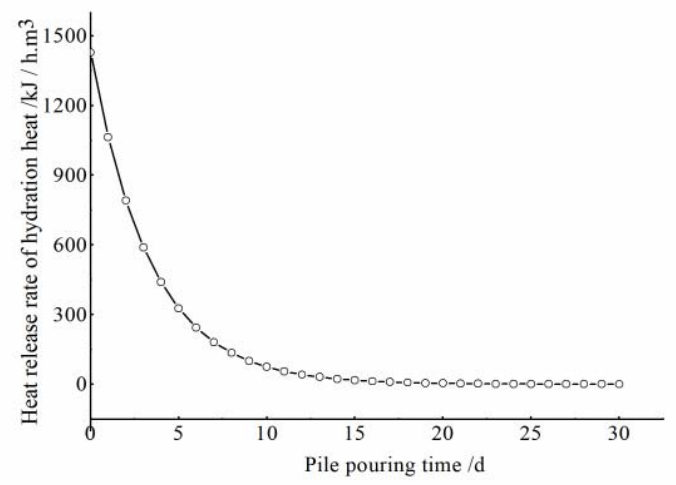

Fig. 3. Curve of concrete heat release rate VS. time

\subsection{Solar radiation and air convection}

The concrete surface exposed to the atmosphere can absorb solar radiation heat, transfer heat by natural convection, and absorb diffuse radiation from the ground and other structures. Upon ignoring the diffuse radiation, the heat conduction equation of the concrete structure exposed to the air is as follows:

$$
\lambda_{\mathrm{c}}\left[\frac{\partial T}{\partial n}\right]=h\left(T_{\mathrm{c}}-T_{a}\right)+\alpha S
$$

Wherein: $\lambda\left(W\left(m \cdot{ }^{\circ} \mathrm{C}\right)^{-1}\right)$ refers to the heat conductivity coefficient of concrete; $h\left(W \cdot \mathrm{m}^{-2} \cdot{ }^{\circ} \mathrm{C}^{-1}\right)$ refers to the heat exchange coefficient in convection and radiation;

$\left({ }^{\circ} \mathrm{C}\right)$ refers to the temperature on the surface of concrete; $\mathrm{n}\left({ }^{\circ} \mathrm{C} \cdot \mathrm{m}^{-1}\right)$ refers to the temperature gradient direction; $\mathrm{T}_{\alpha}\left({ }^{\circ} \mathrm{C}\right)$ refers to the temperature of air close concrete; $\alpha$ refers to the solar radiation absorbility factor of the concrete structure surface; $\mathrm{S}\left(\mathrm{W} \cdot \mathrm{m}^{-20}\right)$ refers to the solar radiation intensity.

Since the upper and lower surfaces of the bearing platform are not directly exposed to the sunlight, the solar radiation heat of upper and lower surfaces of the bearing platform is deemed as zero; assume the solar radiation heat of side face of the bearing capacity and side face of the exposed pile foundation as the average solar radiation heat, with the solar radiation intensity can be calculated according to
Wherein, $\mathrm{S}\left(\mathrm{W} . \mathrm{m}^{-2}\right)$ refers to the annual solar radiation intensity, $\mathrm{t}(\mathrm{h})$ refers to the time.

The heat between surface of bearing platform and exposed piles will be transferred into the air via air convection. Considering the factors that can result in climate warming, the air temperature can be calculated via the sinusoidal function with the annual average temperature $\left(-4.0^{\circ} \mathrm{C}\right)$ :

$$
T_{\mathrm{a}}=3.4+12.2 \sin \left(\frac{2 \pi}{8760}+\theta\right)+A t
$$

Wherein, $A=4.63 \times 10-6{ }^{\circ} \mathrm{C} / \mathrm{h}$, corresponding to the increase of temperature $\left(2{ }^{\circ} \mathrm{C}\right)$ in the future 50 years. $t(h)$ refers to the time. The solar radiation absorbility factor of the concrete structure surface $(\alpha)$ is set to be $0.42^{[8-9]}$, and considering the heavy wind in the plateau, the average heat exchange coefficient on the surface of concrete $\mathrm{h}=4.74 \mathrm{~W} \cdot \mathrm{m}-2 .{ }^{\circ} \mathrm{C}$.

\subsection{Initial conditions and boundary conditions}

Initial conditions:

$$
\left.T(x, y, z, t)\right|_{t=0}=T_{1}
$$

$\mathrm{T} 1$ refers to the initial ground temperature when casting auxiliary piles. Set the ground temperature under 5 years of effect of $0.6^{\circ} \mathrm{C}$ confined water at $20.0 \mathrm{~m}$ under the ground as the initial ground temperature, and the temperature of casting concrete of auxiliary piles is $5^{\circ} \mathrm{C}$.

Since this bridge is located at the band side of a river valley, and there is no effective measure to handle the underground water, the influence of underground confined water on the ground temperature will continue to exist even upon the completion of auxiliary piles. The boundary conditions are as below: 


$$
\begin{array}{cl}
\frac{\partial T}{\partial y}=0 \quad(x=0 m, 26.3 m) \\
\frac{\partial T}{\partial x}=0 \quad(y=0 m, 16.3 m) \\
\left.\frac{\partial T}{\partial z}\right|_{z=-60 m}=0.028^{\circ} \mathrm{C} \\
\left.T(x, y, z, t)\right|_{z=-20 m}=T_{2} \\
\left.T(x, y, z, t)\right|_{Z=-0.5}=-1.5+12.2 \sin \left(\frac{2 \pi}{8760} t+\theta\right)+A t \\
\left.T(x, y, z, t)\right|^{\circ}=5^{\circ} \mathrm{C}
\end{array}
$$

Wherein, $\mathrm{T}_{2}$ refers to the measured temperature of the confined water under the frozen layer $\left(0.6^{\circ} \mathrm{C}\right)$.

In the actual project, heat bars are set around the pile foundation. Since after the construction of the cast-inplace piles, the soil temperature around the pile will inevitably go up, it is difficult to judge whether the heat bars work or not. Therefore, the cooling effect of the heat bars is not considered into the calculation process, and then the bearing capacity in the calculation results will be calculated later.

\subsection{Pile-frozen soil heat conduction}

Heat conduction equilibrium equation of frozen soil surrounding piles is as below:

$$
\rho \mathrm{c} \frac{d T}{d t}=\frac{d}{d x}\left(\lambda \frac{d T}{d x}\right)+\frac{d}{d y}\left(\lambda \frac{d T}{d y}\right)+\rho L \frac{d f_{\mathrm{s}}}{d t}
$$

Wherein, $\rho$ refers to the density of frozen soil $\left(3 \mathrm{~kg} / \mathrm{m}^{3}\right) ; \mathrm{c}$ refers to the specific heat $\left(\mathrm{J}\left(\mathrm{kg} /{ }^{\circ} \mathrm{C}\right)\right) ; \mathrm{L}$ refers to the latent heat of phase change of water, $\mathrm{L}=$ $334 \mathrm{~kJ} / \mathrm{kg}$; $\mathrm{x}, \mathrm{y}$ and $\mathrm{z}$ respectively are the rectangular coordinates; $f_{s}$ refers to the solid fraction, with the increase (or decrease) of solid fraction $\left(f_{s}\right)$ in direct proportion to the release (or absorption) of latent heat of phase change. Therefore:

$$
f_{s}=\left(T_{L}-T\right) /\left(T_{L}-T_{S}\right)
$$

Wherein, $T_{L}$ and $T_{S}$ respectively refer to thawing temperature and freezing temperature $\left({ }^{\circ} \mathrm{C}\right) ; \mathrm{T}_{\mathrm{d}}$ refers to the temperature of node within the phase-change area $\left({ }^{\circ} \mathrm{C}\right) ; \lambda$ in the phase-change area can be interpolated according to the corresponding temperature value (T), with the thermophysical parameters of pile foundation and frozen soil abstracted from study of $\mathrm{Wu}$ Yaping et at. ${ }^{[6]}$

\section{Numerical Results}

\subsection{Geothermal field of pile-soil system after casting auxiliary piles}

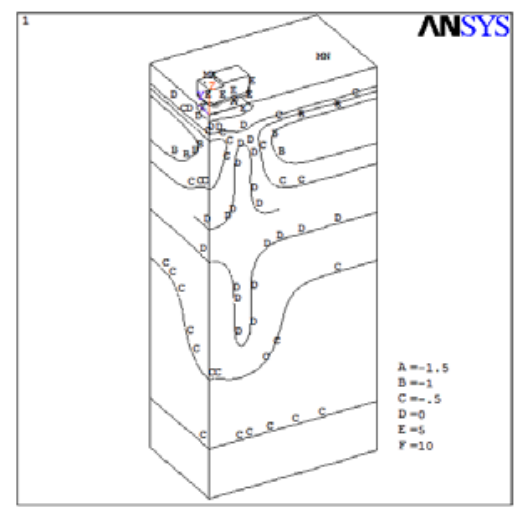

Fig. 4. Temperature field of pile-soil system after 2 months

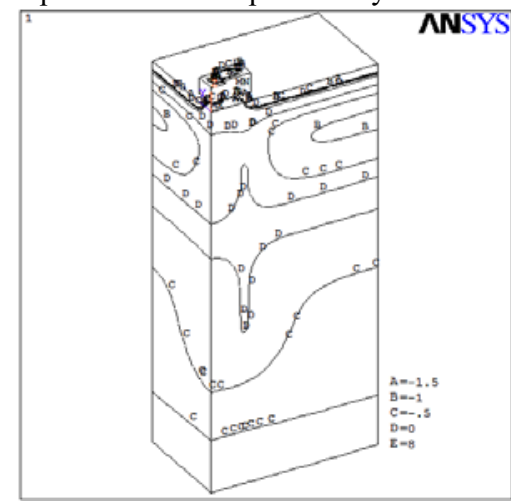

Fig. 5. Temperature field of pile-soil system after 4 months

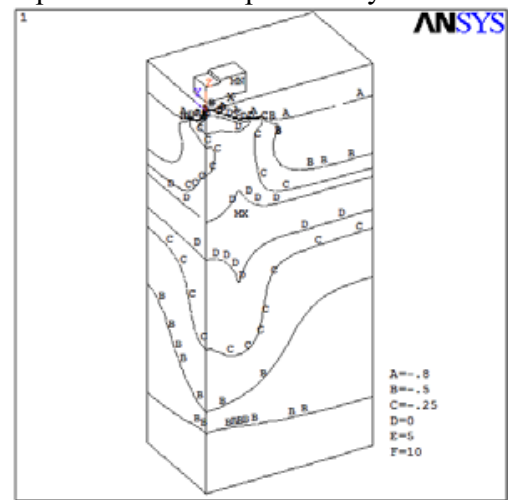

Fig. 6. Temperature field of pile-soil system after 6 months

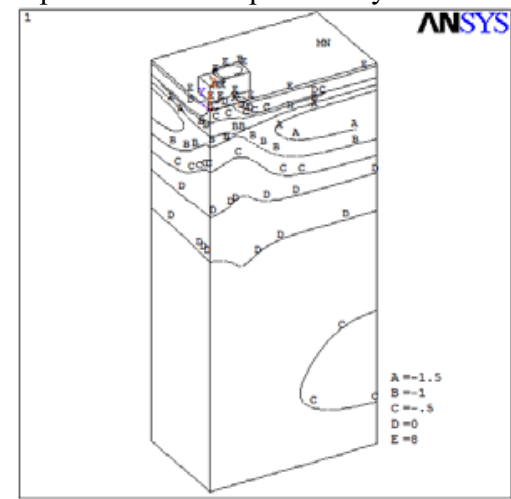

Fig. 7. Temperature field of pile-soil system after 12 months 


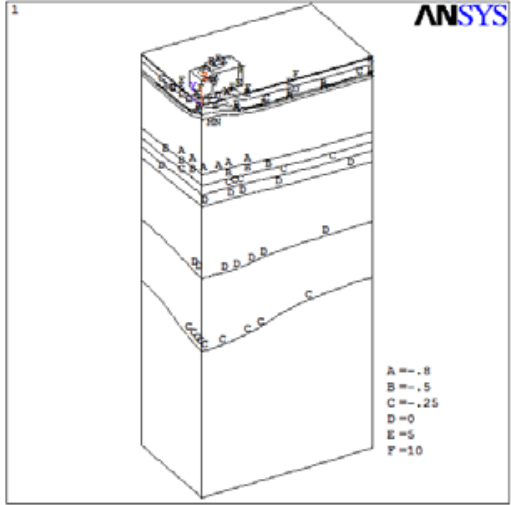

Fig. 8. Temperature field of pile-soil system after 5 years

As shown in Figure 4, the ground temperature surrounding the piles, 2 months after pile casting, under the influence of the initial temperature of the concrete used for the casting auxiliary piles and of the cement hydration heat, goes up; meanwhile the frozen soil between the two adjacent auxiliary piles thaws, and form the "melting zone". As shown in Figure 5, 4 months after pile casting, the "melting zone shrinks". As seen in Figure 6, the ground temperature around the auxiliary piles is significantly higher than that at a distance. Furthermore, due to the influence of groundwater $\left(0.6{ }^{\circ} \mathrm{C}\right)$, there is still a melting layer at the depth of around $20.0 \mathrm{~m}$ underground, and the "melting layer" around the auxiliary piles is thicker. One year after pile casting, the influence of concrete hydration heat and of temperature of casting concrete on the ground temperature still remains. As shown in Figure 7, the temperature isoline is still a curve at the depth of $20.0 \mathrm{~m}$ underground, with the ground temperature close the piles still being slightly higher than the ground temperature at a distance. In the fifth year (Figure 8), the temperature isoline at deeper underground places becomes flat, which means the ground temperature around the piles is the same as the ground temperature at a distance. At this time, we can assume that the influence of cement hydration heat and of initial temperature on the ground temperature brought by the pile casting has been absorbed and diffused by the surrounding frozen soil.

\subsection{Pile-soil interface temperature}

\subsubsection{Pile-soil interface temperature of auxiliary piles}

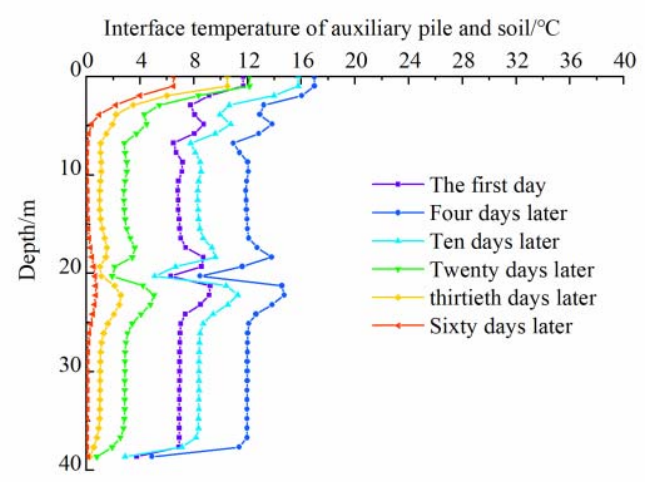

Fig. 9. Initial temperature change of pile-soil interface

As shown in Figure 9, from the 1st day to the 4th day of pile casting, the heat release of hydration heat is at a fast speed, and the heat failing to be released will warm up the auxiliary piles. As a result, the temperature of auxiliary piles goes up gradually, and reaches the peak value at the 4th day. Later, the release of cement hydration heat slows down, and along with the diffuse of heat into the surrounding foundation soil, the temperature of auxiliary piles gradually declines. On the 30 th day of pile casting, the pile-soil interface temperature of the auxiliary piles is still higher than $0^{\circ} \mathrm{C}$, namely, the auxiliary piles have not been refrozen 30 days after pile casting. In the early stage of pile casting, there is a $0.6^{\circ} \mathrm{C}$ flowing groundwater at the depth of about $20.0 \mathrm{~m}$ underground, at which time the groundwater temperature is lower than the auxiliary pile temperature, and the flowing water can take away the cement hydration heat. As a result, the pile body temperature at the depth of $20.0 \mathrm{~m}$ underground is lower than that at other depths. On the 60 th day of the casting of auxiliary piles, the temperature of the auxiliary piles at the depth of $20.0 \mathrm{~m}$ underground is still $0.6^{\circ} \mathrm{C}$ due to the effect of groundwater, and the heat of the auxiliary piles at other depths is transferred to the foundation soil surrounding the piles. As a result, the ground temperature is lower than $0.6^{\circ} \mathrm{C}$, but the soil is still not refrozen, namely, the temperature is higher than $0^{\circ} \mathrm{C}$.

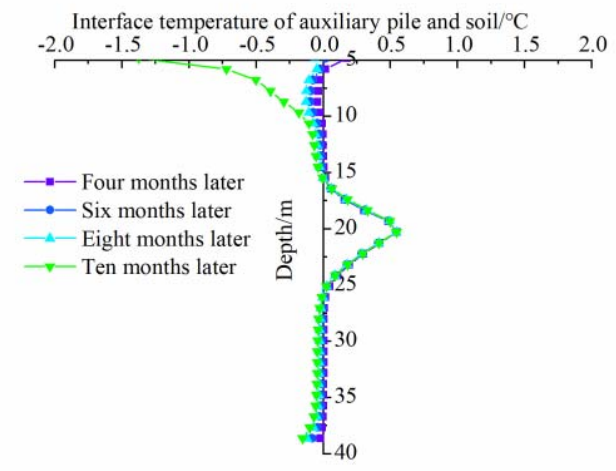

Fig. 10. Temperature change of pile-soil interface in the first year

As shown in Figure 10, in the $4^{\text {th }}$ month, the 
temperature of cast-in-place piles at the depth of 15$25 \mathrm{~m}$ underground is higher than $0^{\circ} \mathrm{C}$ due to the influence of groundwater at $0.6^{\circ} \mathrm{C}$, and the pile-soil interface temperature at other depths starts to be slightly lower than $0^{\circ} \mathrm{C}$, namely, the cast-in-place piles begin to freeze gradually in the $4^{\text {th }}$ month.

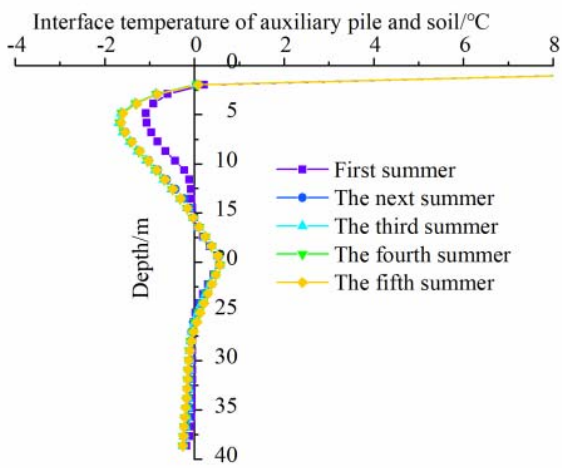

Fig. 11. Temperature change of pile soil interface in summer

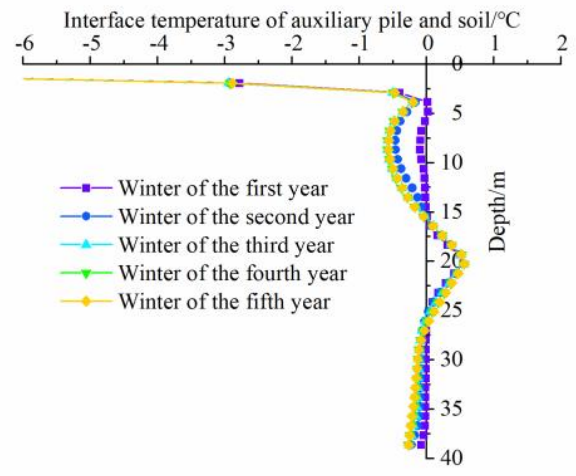

Fig. 12. Temperature change of pile soil interface in winter As shown in Figure 11 and Figure 12, the pile-soil interface temperature at the depth of $2-15 \mathrm{~m}$ underground in the first year of pile casting is higher than that in the second year, and the pile-soil interface temperature from the 2 nd year to the 5 th year does not vary significantly, namely, the temperature of the pile body, affected by the initial temperature of casting concrete and hydration heat in the first year after the construction of cast-in-place piles, is relatively higher and not stable.

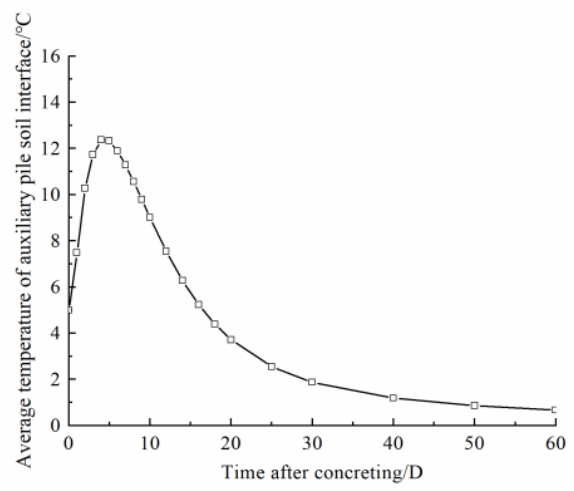

Fig. 13. Temperature change of pile-soil interface in initial stage

As shown in Figure 13, the initial temperature of casting concrete into auxiliary piles is $5^{\circ} \mathrm{C}$, and the average temperature of pile body on the 1st day of pile casting, due to the influence of cement hydration heat, goes up to $7.5^{\circ} \mathrm{C}$, then $10.3^{\circ} \mathrm{C}$ on the 2 nd day, $11.8^{\circ} \mathrm{C}$ on the $3^{\text {rd }}$ day, $12.4^{\circ} \mathrm{C}$ (the maximum value) on the $4^{\text {th }}$ day, and slightly goes down to $12.3^{\circ} \mathrm{C}$ on the $5^{\text {th }}$ day, then $11.9^{\circ} \mathrm{C}$ on the $6^{\text {th }}$ day. Later, since the cement hydration heat gradually transfers into the foundation soil surrounding the piles, the average temperature of pile body continues to go down, and become $0.04^{\circ} \mathrm{C}$ on the $60^{\text {th }}$ day.

\subsubsection{Pile-soil interface temperature of original piles}

Since the original pile is only $2 \mathrm{~m}$ away from the auxiliary piles, cast-in-place auxiliary piles will warm up the soil around piles, which will serve as the medium and transfer the heat of the auxiliary piles to the original pile foundation. As a result, the temperature of the pile-soil interface of the original pile foundation goes up, and its bearing capacity goes down.

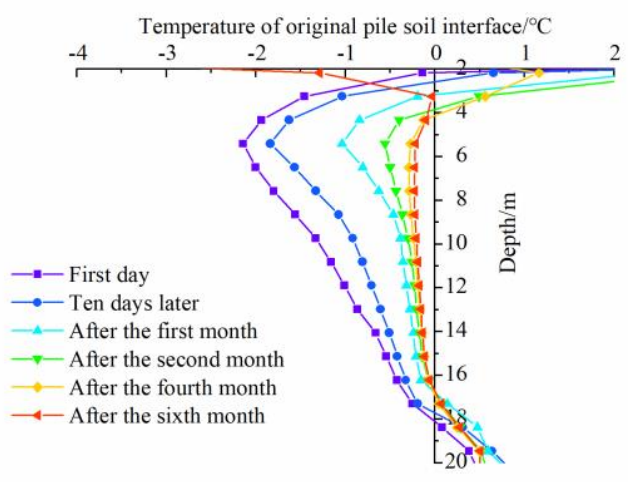

Fig. 14. Initial temperature change of pile-soil interface

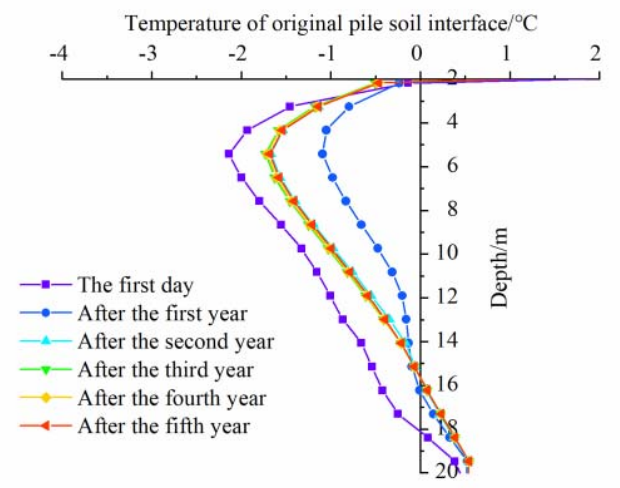

Fig. 15. Temperature change of pile soil interface in summer 


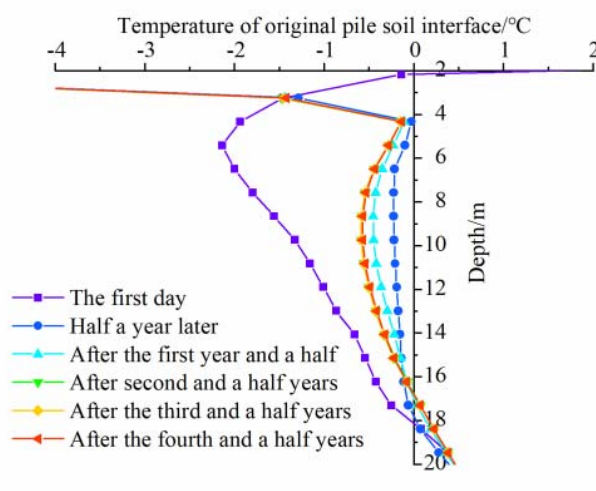

Fig. 16. Temperature change of pile soil interface in winter

As shown in Figure 14, the thermal disturbance imposed on the foundation soil under the pier due to hydration heat and the temperature of casting concrete upon casting auxiliary piles, will significantly warm up the original pile foundation. Since the $10^{\text {th }}$ day of cast-in-place auxiliary piles, the temperature on the surface of original pile foundation will explicitly go up, and then reach the highest temperature by the $6^{\text {th }}$ month.

According to Figure 15 and Figure 16, the thermal disturbance imposed on the foundation soil under the pier due to hydration heat and the temperature of casting concrete upon casting auxiliary piles, will significantly warm up the original pile foundation, and thus disturbance will last for a long time. Even at the $5^{\text {th }}$ year after completing the construction of castin-place auxiliary piles, the temperature of original pile foundation still goes up, and has not went down to the temperature before being disturbed. In this way, the heat caused by casting auxiliary piles does not completely dissipate, and its influence on the ground temperature under the pier can be enduring.

Place the figure as close as possible after the point where it is first referenced in the text. If there is a large number of figures and tables it might be necessary to place some before their text citation. If a figure or table is too large to fit into one column, it can be centred across both columns at the top or the bottom of the page.

\section{Foundation Bearing Capacity Analysis}

The original pile of the railway bridge is $22 \mathrm{~m}$ long and $1.25 \mathrm{~m}$ in diameter, while the auxiliary pile is $38.6 \mathrm{~m}$ long and $1 \mathrm{~m}$ in diameter. The increase of pile-soil interface temperature will undercut the tangential freezing strength between piles and soil around piles, and the increase of foundation soil temperature at the bottom of piles even can melt the foundation soil, and jeopardize the allowable bearing stress of foundation soil at the bottom of piles. As a result, the increase of pile-soil interface temperature will directly lead to the decrease of bearing capacity of pile foundation. When calculating the bearing capacity of pile foundation, it should be notified that when the temperature of the foundation soil at the bottom of piles is higher than $0^{\circ} \mathrm{C}$, the foundation soil at the bottom of piles is deemed as failing to provide sufficient bearing capacity.

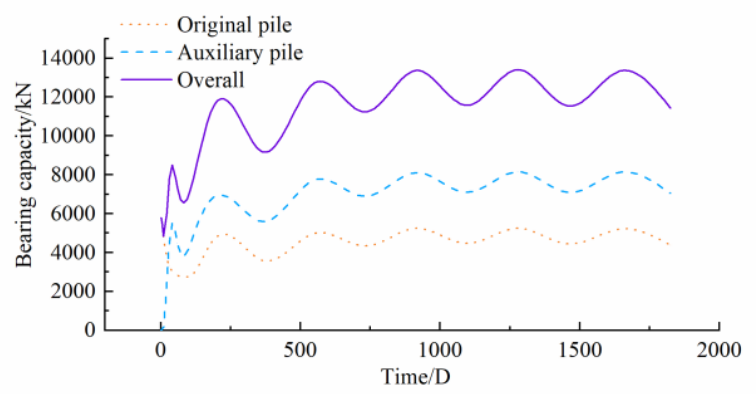

Fig. 17. Curves of foundation bearing capacity VS. time

As shown in Figure 17, when casting auxiliary piles, the bearing capacity of the original piles decreased at the initial stage of casting along with the increase of pile-soil interface temperature under the influence of cement hydration heat, and two months later, the bearing capacity decreased significantly from the original $5,786.0 \mathrm{kN}$ to $2,829.2 \mathrm{kN}$. At the early stage of casting the auxiliary piles, the strength of concrete is not up to the requirement due to its concrete age is not old enough, so it does not have the bearing capacity. One month later, the pile-soil interface temperature of auxiliary piles is slightly higher than $0^{\circ} \mathrm{C}$, and its bearing capacity can be calculated in the form of friction piles, with the bearing capacity being 4,474.5 kN. Later, the frozen soil around piles will get refrozen, with the pile-soil interface temperature being lower than $0^{\circ} \mathrm{C}$. At this moment, the bearing capacity will gradually increase along with the refreezing of pile-soil interface temperature. Six months after casting, it comes to winter (cold season), its bearing capacity is up to $6,741.4 \mathrm{kN}$. One year after casting, it comes to summer(warm season), the pile-soil interface temperature at the place near the surface, under the effect of external air temperature, will go up, and the bearing capacity in summer (warm season) decreases accordingly.

The initial bearing capacity of original piles in summer (warm season) is $5,786.0 \mathrm{kN}$. As shown in Figure 17, 1 year after casting auxiliary piles, it comes to summer (warm season), the bearing capacity of original piles is $3,593.7 \mathrm{kN}$, namely, the decreased bearing capacity caused by increasing pile-soil interface temperature under the effect of cement hydration heat has not restored to that before being disturbed 1 year later; 3 years after casting auxiliary piles, the bearing capacity of original piles slightly increases to $4,472.0 \mathrm{kN}$, but still fails to restore to that before being disturbed. In the following two years, after taking into consideration of factors of climate warming, the bearing capacity of original piles declines slightly. The bearing capacity of the auxiliary piles 1 year after casting (summer/warm season) is $5,584.6 \mathrm{kN}$, and in the following two years, the bearing capacity of the auxiliary piles gradually increases with the refreezing of the auxiliary piles, and reaches the highest in the 3rd year. In the following two years, after taking into consideration of factors of climate warming, the bearing capacity of original piles 
declines slightly. In general, the overall bearing capacity after casting auxiliary piles is enhanced, and the bearing capacity in winter (cold season) is higher than that in summer (warm season). Moreover, the bearing capacity can form half a year after casting auxiliary piles.

For the measure of enhancing the bearing capacity by adding auxiliary piles and integrating with the original piles into a whole, the bearing capacity increases along with the increasing pile-soil interface temperature of original piles under the effect of hydration heat and temperature of casting concrete, and such influence is enduring. However, 5 years after casting, the bearing capacity still fails to restore to that before being disturbed. For the auxiliary piles, the pile-soil interface temperature of most piles 6 months after casting is lower than $0^{\circ} \mathrm{C}$, and is higher than $0^{\circ} \mathrm{C}$ at the depth of $20 \mathrm{~m}$ underground due to the effect of the confined water at $0.6^{\circ} \mathrm{C}$, namely, the bearing capacity of the auxiliary piles can form in half a year. In general, adding auxiliary piles and integrating with the original piles into a whole can actually enhance its bearing capacity.

\section{Conclusion}

The bearing capacity increases along with the increasing pile-soil interface temperature of original piles under the effect of hydration heat and temperature of casting concrete, and such influence is enduring. However, 5 years after casting, the bearing capacity still fails to restore to that before being disturbed.

The overall bearing capacity after casting auxiliary piles can be enhanced, and the bearing capacity in winter (cold season) is higher than that in summer (warm season), namely, the bearing capacity can form half a year after casting auxiliary piles.

The measure of enhancing the bearing capacity by adding auxiliary piles has both pros and cons. On the one hand, auxiliary piles themselves, upon being refrozen, can jointly construct the bearing capacity with the original pile foundation, and on the other hand, the bearing capacity will be undercut along with the increase of original foundation soil temperature under the effect of concrete hydration heat during the construction of cast-in-place auxiliary piles. Cast-in-place auxiliary piles can enhance the overall bearing capacity, which will not only increase its overall bearing capacity at the initial stage, but also undercut its overall bearing capacity for the moment. The overall bearing capacity can form only after the frozen soil gets refrozen later.

\section{References}

1. W. Ma, D.Y. Wang, Chinese journal of geotechnical engineering. J. 30, 625 (2012)

2. G.D. Chen, H.J. Jing, Hydrogeology\&engineering geology. J. 40, 1 (2013)

3. L.X. Zhang, Academy of Railway Sciences. J. 3, 37 (2000)
4. Tsytovich H A. Mechanics of frozen soil (Zhang Changqing, Zhu Yuanlin, trans. Beijing: Science Press, 1985)

5. Ma Wei, Wang Dayan. Mechanics of frozen ground( Beijing: Science Press, 2014)

6. Y.P. Wu, C.X. Guo, W.D. Pan, Chinese Journal of Rock Mechanics and Engineering. J. 23,4229 (2004)

7. C.X. Guo, Y.P. Wu, Chinese Journal of Rock Mechanics and Engineering. J. 33, 3306 (2014)

8. J.R. Zhang, X.D. Xv, W.Y. Liu. Building-Science. J. 22, 42 (2006)

9. W.Y. Liu, Y.M. Di, China concrete and cement products. J. 22, 42 (2006)

10. J.R. Zhang, Z.Q. Liu, W.Y Liu, Sichuan Building Science. J. 33, 143 (2007)

11. Y.P. Wu, Y.L. Zhu, C.X. Guo, Science In China (Ser.D Earth Sciences). J. 48, 968 (2005)

12. Y.P. Wu, J. Guo, C.X. Guo, Zhejiang Univ-Sci A (Appl Phys \& Eng). J. 11, 88 (2010) 